\title{
SUBJETIVACIÓN, IRRACIONALISMO, MÚSICA: RASGOS DEL SIMBOLISMO EN LA POESÍA ESPAÑOLA HACIA 1900
}

\author{
Ángel L. PRIETO DE PAULA \\ Universidad de Alicante
}

Cuando se habla de poesía, deberíamos desechar un procedimiento de análisis muy habitual, aunque contrario a las maneras de la inteligencia, consistente en situarse en el prejuicio para hacer coincidir luego con él la realidad escrutada, lo que resulta relativamente fácil: basta buscar aquello que necesitamos encontrar. Las disensiones o particularidades individuales de los artistas respecto a los rasgos generales de su siglo pueden ejemplificar lo que se pretenda: toda edad histórica nos proporciona unas cuantas concreciones que parecen confirmar lo que -incluso si estamos guiados por una intuición recta- hemos decidido con antelación. En el ámbito de la segunda mitad del XIX y primeros años del XX, abundan las protestas de los escritores contra los elementos característicos de su tiempo, lo que nos empuja a pensar que la poesía siempre se ha equivocado de era, o, si no, que los poetas son constitutivamente, tal como quiere el tópico, espíritus inadecuados a la realidad. Con evidente tono sarcástico, Bécquer trata del materialismo decimonónico, en su vertiente poética, cuando se dirige a una «Mujer al fin del siglo diez y nueve / material y prosaica» para comunicarle que «pienso cual tú que una oda sólo es buena / de un billete del Banco al dorso escrita» (rima XXVI de la edición de 1871; número 7 en Libro de los gorriones)'.

'En el estudio-edición de las Rimas becquerianas preparado por Luis García Montero (García Montero, 2001), esta rima es la número 8. La reordenación que hace de las mismas atiende a la disposición del Libro de los gorriones, a fin de cuentas «el único orden becqueriano que nos consta, sea 
Al ocuparnos de la poesía española en los umbrales de 1900, el prejuicio instrumental más socorrido es el sometimiento de la misma a los rasgos estéticos de un Simbolismo que no siempre nos tomamos la molestia de definir. El objeto de esta reflexión es precisar la nervadura conceptual que subyace a la poesía de esta etapa, bajo diversas manifestaciones anecdóticas o no sustantivas que se mezclan con las esenciales, y pueden provocar confusión. Dada la vastedad de la propuesta, me limitaré a señalar unos trazos teóricos que cuentan en todos los casos con sólidas apoyaturas textuales, cuya evidencia me ahorra tener que traerlas explícitamente a colación.

Propongamos, para arrancar, un lugar común: los cambios estéticos de la época de entresiglos vendrían remitidos a una pretendida crisis cuya entidad trasciende lo específicamente literario e impregna los diversos apartados del espíritu. $\mathrm{Y}$ ahora toca mostrarse reticentes: sabemos bien que, contemplados de cerca, todos los tiempos lo son de crisis, idea en la que coincidirán a buen seguro la Historia de la Filosofía y la Filosofía de la Historia. Como Jardiel Poncela cuando se preguntaba en el título de una de sus novelas si hubo alguna vez once mil vírgenes, podemos inquirir aquí si hubo algún tiempo que no lo fuera de crisis; de manera que el socorrido comodín servirá de bien poco si no concretamos las peculiaridades de «esta» crisis; lo cual significa, para no escurrirnos entre las rendijas de la vaguedad, precisar la Weltanschaaung diltheyana que determina los rasgos distintos que se dan en poesía española momentos antes de que se produjera la eclosión modernista en España (en torno a 1903). Y al hablar de «rasgos distintos» me refiero a aquellos que son específicos respecto a los también específicos de la época anterior; no intercambiables con otros comunes de otros momentos históricos; y no provenientes sin más de la herencia.

Considerado a vista de pájaro, parece pertinente restringir el término «crisis» a aquellas inflexiones históricas, así como a sus manifestaciones artísticas correlativas, cuya novedad no puede explicarse tan sólo por un desarrollo progresivo de lo preexistente; de tal forma que los antiguos hábitos y códigos culturales dejan de ser operativos en una situación inédita, que no atiende a parámetros conocidos o previsibles a partir de lo conocido. Y decimos que no puede explicarse tan sólo por ello; no que pueda prescindirse de ello en dicha explicación. Hablando de poesía española posterior al siglo XV, sólo hay, según entiendo, dos auténticas revoluciones que suponen un profundísimo cambio cosmovisionario

lógico o no» (p. 125); si bien con algunas modificaciones que se fundan en la idea de que la mano de Bécquer fue la que corrigió el manuscrito. Una de estas modificaciones, consistente en este cambio de orden de la rima 7 de Libro de los gorriones, se debe a la colocación en primer lugar de la antigua rima 11 ( YYo sé un himno gigante y extraño»). El estudio en cuestión ofrece luces que alumbran los temas que tratamos aquí, y materia para la revisión y discusión de conceptos establecidos. 
(ninguna de las cuales, digámoslo ya, coincide con la producida en el período y la estética dominantes a que nos referimos en estas páginas): una en el Renacimiento, otra en el Romanticismo.

La primera revolución supuso, en lo poético, la irrupción de un sujeto objetivado -acaso sería más exacto hablar de objetivación del sujeto-, al convertirse en forma artística los avatares del yo, una vez sometida la experiencia personal a las pautas normativas de la cultura. En el ámbito de la poesía castellana, es eso lo que hace Garcilaso de la Vega cuando extrae de las bodegas de la biografía unos temas que formarán masa con otros motivos estrictamente culturales: en la Égloga III, Elisa -el elemento más reconocible como real, que en la Égloga I todavía presentaba irisaciones impudorosamente biográficas, a pesar de los disfraces pastoriles- a la par y con el mismo rango que Venus, Eurídice, Dafne. Lo que, por supuesto, implicaba otra correspondencia: el yo (sujeto poético) relativo a Elisa (Isabel Freire, cada vez más en lontananza) alcanzaba el rango de los amantes mitológicos Adonis, Orfeo y Apolo, produciéndose de este modo la salvación del dolor por el desleimiento y sublimación del yo en el mar de la cultura codificada.

La segunda revolución, la romántica, implicó más bien la evisceración de ese mismo yo que había sido reglado en el Renacimiento, y que sale de la vaina del canon para mostrar con ostentación sus heridas y sus muñones, desbordando las previsiones normativas que regulan las propensiones individuales a la convergencia en un arquetipo platónico. Se trata, por lo dicho, de un movimiento inicialmente diseminativo y centrífugo, en virtud del cual el sujeto biográfico rompe las constricciones del modelo y exhibe su intimidad como tal intimidad, hasta generar con ella otras creaciones tópicas que consolidarán en el universo de la cultura. Al final, ésta termina siempre engullendo las pulsiones individuales, que a partir de ahí alimentan los nuevos dechados o modelos reconocibles -esto es, ya formalizados- por los demás hombres. Es el caso de Espronceda cuando proyecta en el alma hermana de la hermosa Jarifa el hastío del mundo que a ella y a él les ha matado el ansia de vivir, y que poco después queda mineralizado en un locus cultural que identificamos, desvinculado ya de sujetos o protagonistas, con el mal du siècle romántico.

Fuera de estos dos grandes momentos críticos, existen también, por supuesto, otras tracciones de la historia; pero se sitúan en un ámbito cuyos elementos de acción son ya actuantes. No hay en el Barroco nada sustantivo que no esté germinalmente en el Renacimiento; pero es cierto que a partir de éste se ha producido una fortísima radicalización -en buena medida por el afán de liberar la poética renacentista de la anquilosis retórica adonde la aboca la propia reiteraciónque termina por generar una estética que contesta a aquella que le precede y de la 
que procede. De parecida manera, lo esencial simbolista está inscrito en los códigos poéticos del Romanticismo -sin que de ello derive una gradación cualitativa prefijada-, toda vez que éste elabora, a partir de Kant y Schiller, una teoría anticlasicista básicamente homogénea en la que están contenidos in ovo los siguientes hitos de desarrollo idealista, que no son otros que «el simbolismo y su familia artística y doctrinal (prerrafaelismo, decadentismo, impresionismo, hermetismo, modernismo...)» (Aullón de Haro, 2000: 31). Y si esto es así cuando la evolución lleva parejo un cierto anhelo de ruptura con los modelos de partida, debido a la insatisfacción o sensación de insuficiencia respecto al tipo dominante, mucho más ocurre cuando las innovaciones lo son por mera evolución o suma de recursos. Así, ¿qué importancia tiene que el bueno de don Tomás de Iriarte se haya anticipado a los modernistas en la utilización de numerosas estrofas, si en él la métrica es una circunstancia de compás mientras que en Rubén es la forma de canalización de un espíritu? Si se distinguiera efectivamente entre innovaciones parciales o circunstanciales y las auténticas innovaciones vertebrales, creo que no se pondría tanto énfasis en inventarse unos «modernistas» españoles prerrubenianos, cuya familiaridad con el auténtico Modernismo sólo es algo más estrecha que la que podría encontrarse en el citado Iriarte.

Procuraremos, pues, especificar esas notas peculiares que tomaron cuerpo en la estética simbolista, y que produjeron los primeros frutos granados en la poesía española hacia 1902 o 1903 -Alma, de Manuel Machado; Arias tristes, de Juan Ramón; Soledades, de Antonio Machado-, bastantes años después de que Moréas, el autor del manifiesto en 1886, hubiera decretado la declinación del movimiento, que de todos modos en Francia podía darse por amortizado en 1897. Ciertamente, los títulos citados u otros coetáneos de menor significación habrían de ser o continuados o contestados por diversos libros que fueron apareciendo en los años siguientes, pero que no pueden entenderse sin los primeros, dado que toman la sensibilidad simbolista como referente, bien subrayando las sutilezas intelectuales (Pérez de Ayala, La paz del sendero, 1904), bien sazonándola con rasgos medievalizantes y prerrafaelitas (Valle-Inclán, Aromas de leyenda, 1907), bien enarbolando, incluso, la bandera del antisimbolismo (Unamuno, Poesías, 1907). Basándonos en los títulos más adecuados a la estética simbolista, y en aquellos que se alejan de su centro pero no pueden explicarse sin ella, ¿cuáles son los elementos cuya concurrencia provoca en España el cambio poético? ¿Por qué unos rasgos estéticos que venían de atrás, y que podrían llamarse simbolistas avant la lettre, se espesan en estos años? ¿Puede conocerse el filtro que provoca que unos caracteres del Romanticismo adquieran ahora mayor intensidad, otros ingresen tamizadamente en el sistema, y algunos sean excluidos del mismo? La respuesta a estas preguntas queda fuera de la modesta pretensión de estas pági- 
nas; pero no quisiéramos cerrarlas sin haber aportado al menos un grano en su contestación.

Situar la esencia de la poesía de entresiglos dentro de una línea de familia que arranca del Romanticismo no significa minimizar o desdeñar su esencia renovadora, ni mucho menos, ni tampoco negar otros precedentes: en poesía, la originalidad no es privativa de quien llega primero. La cuestión de si un segmento estético representa el epigonalismo o la plenitud en relación con el que le antecede $-o$, visto desde el otro extremo, si el que le antecede es la plenitud o sólo el precedente inmaduro respecto del que le sigue- depende de factores muy poco precisables. Entre ellos no hay que desestimar el juicio cambiante de las diversas generaciones de lectores; ni tampoco la manera que tiene una estética de insertarse en la tradición y modos de un determinado enclave cultural: el Barroco francés presenta rasgos de degradación y extravío de los que carece, al menos en su valoración más negativa, el español, el cual se radica en un tejido cultural que lo asimila sin violencia. Por lo demás, si analizamos los antecedentes estéticos del Simbolismo como corriente que singulariza mejor la época a que nos venimos refiriendo, notaremos que, pese a su vinculación genética con el espíritu romántico, no estamos ante una nueva presentación del Romanticismo tal como se manifestó medio siglo atrás, adaptado a las particularidades de fines del Ochocientos. Diversos precedentes ajenos al espíritu romántico desautorizan esta consideración. Es más cierto que, en España, la estética simbolista concretó teóricamente, y actualizó estéticamente, una larga y discontinua línea que arranca nada menos que de ciertos espirituales del siglo XVI -San Juan de la Cruz- y que tiene entre los tardorrománticos españoles seguidores tan importantes como Bécquer, cultivadores unos y otros de las diversas técnicas elípticas, sincopaciones e intuiciones paralógicas que corresponden a una profunda desconfianza ante las capacidades denotativas de la palabra, cuyas carencias pueden ser verbales o deberse a la indefinición del objeto extrapoético a que se aplican.

Hablamos, pues, grosso modo, de tres siglos de vigencia de una actitud estética, muchas veces implícita, casi siempre recoleta y silenciosa, pocas veces manifiesta, nunca ostentosa y gárrula (algo, por otra parte, que es contrario a su especificidad artística); aunque hasta la segunda mitad del XIX dicha actitud no se conforma en una Poética positiva (en la escasa medida que el Simbolismo, refractario a reglamentaciones y sistemas, admitiría). Es precisamente esta condición no pautada, que acabamos de denominar borrosamente actitud, la que le permite sobrevivir y mantenerse subrepticiamente en tanto que otras estéticas vigentes entran en un proceso irreversible de descomposición. Así las cosas, no parece exagerado afirmar que su presencia matizada, no formalizada y casi táci- 
ta, ha aminorado su importancia en la historia de la literatura; pero esa misma suerte de existencia letárgica le ha garantizado también la pervivencia. Médula central de esta orientación, al margen de las varias presentaciones estéticas que la recubren, es el abandono de la precisión descriptiva y referencial, basado bien en un juicio de valor negativo sobre la realidad susceptible de verbalización, bien en la asumida incapacidad de las palabras para referir realidades elevadas. En la amplitud del territorio existente entre uno y otro extremos, desdén de lo real o éxtasis de la dicha, caben creaciones tan dispares como el poema «Adelfos» manuelmachadiano de Alma -título que expresa el desvaimiento somático que preside el libro-, o la Noche oscura sanjuanista. El objeto que puede ser dicho no compensa un ejercicio artístico que ha tomado conciencia de la indigencia de aquél, mientras que aquello importante de verdad no puede ser dicho; razón por la cual la verbalización deberá distanciarse de un procedimiento locutivo puramente denotativo, por necesidad insatisfactorio, y pasa a referir el objeto de una manera invertida, mostrando las sombras de su estancia en un contraluz representativo, $o$, si se quiere, a través de las señales de esa incapacidad; pues es sabido que, como escribió Hjelmslev glosando a Kierkegaard, «en una lengua y sólo en una lengua podemos 'ocuparnos de lo inexpresable hasta expresarlo'» (Hjelmslev, 1974: 153). Lo que en esencia comporta el Simbolismo es un anhelo de ocupación de una terra incognita en la que se pronuncia la indecibilidad rilkeana. De este modo, el bagaje retórico tiene su centro en la indefinición -que en otro sistema sería considerada un defecto- en vez de en la precisión denotativa; en el «mareo de lo indeterminado» -son palabras de Campoamor-que enlaza con unas notas que el Romanticismo tardío habría de exaltar, como son el «histerismo soñador» y la brumosidad contraria a la nitidez de las formas (Campoamor, 1890: 115-116).

De lo que llevamos dicho, podemos ya concretar algo: el Simbolismo, al apostar por el más allá como materia susceptible de poetización, actúa en detrimento de lo fenoménico o lo aparencial. En este sentido, una estética que rehúsa el revestimiento de «lo real» evidente con palabras y ritmos poéticos está caminando al lado de una epistemología que entiende la realidad no como lo que llamamos así al bulto, sino más bien como lo que se oculta tras ello o bajo ello. La poetización deja de identificarse con un ejercicio de recubrimiento verbal, mejor o peor efectuado, y pretende activar los asaltos al ergotismo, mistificador en el fondo, mediante toda una panoplia de recursos que remueven el automatismo de la lógica diurna que actuaba en la poesía de discurso racionalista. En relación con esta remoción ha de entenderse la desconfianza en el texto eslabonado racionalmente, toda vez que el encadenamiento racionalista lo es tanto en un sentido metafórico -concatenación silogística, engarce en progresión de los formantes 
lógicos, evitación de saltos en el vacío- como más literal -aherrojamiento, encarcelamiento de un espíritu sujeto a los grilletes del pensar sucesivo-. El descrédito del logocentrismo, que establece inferencias propedéuticamente conducentes al tabernáculo del saber, exige otro tipo de canalización productora de sentido, una serie de pautas que en este caso son las que provienen de las pulsiones musicales que marcan el ritmo con el tam-tam insomne y obsesivo de una intimidad sin compuertas.

De entre todos los rasgos simbolistas de procedencia romántica, quizás el más evidente sea la consideración numénica de lo poético, que hace del escritor un vate con capacidades para auscultar el universo y percibir lo que el resto de los hombres no puede notar: el latido del mundo, el alma de las cosas, la naturaleza animada, los objetos que, muy azorinianamente, viven y sienten, se duelen, gimen. Cierto que, en palabras de Rubén Darío, no hay «mayor pesadumbre que la vida consciente», y que testimonios de la identificación entre consciencia y acuidad en la percepción del dolor hay a miles, en Rubén, en Ganivet, en Unamuno. Ya en los escritores antecedentes se había sustanciado el problema; en «Tristezas», Núñez de Arce, tras preguntarse «¿Qué es la ciencia sin fe?», se dirige a Cristo para expresarle que «La ciencia audaz, cuando de ti se aleja / en nuestras almas deja / el germen de recónditos dolores». Pero si en los autores de esa generación la opción disyuntiva se plantea en términos más drásticos y excluyentes, obedientes a la creencia religiosa muy a duras penas compatible con la ciencia, o a ésta frente a aquélla, en los que se forman durante la Restauración resulta más evidente el abandono del talante combativo, que nace de la convicción, sustituido por el talante lamentatorio ante ese dilema que, alternativamente, deja a los hombres ayunos o de felicidad o de razón ${ }^{2}$. Junto a lo dicho, que establece una línea discriminatoria entre seres inteligentes e hiperestésicos, por un lado, y seres anestésicos, por otro, existe una tristitia rerum -el sintagma que usó Villaespesa como título de un libro-, una tristeza de las cosas que rompe las celdas de la incomunicación y propicia una penetración perceptiva y sentimental de los objetos en la conciencia subjetiva que había afinado antes el Romanticismo. Más abajo lo trataremos en otro plano, pero esta vivificación de los objetos del mundo tiene todas las características de la difusión del ánima subjetiva; en sustancia, un desbordamiento del yo que caracteriza los nuevos tiempos y que incidirá en la propia configuración de los géneros literarios, según veremos ensegui-

${ }^{2}$ Son abundantes los testimonios literarios que tratan de buscar la unión de contrarios entre progreso científico y tecnológico, por un lado, y fe religiosa, por otro. En el poema «Dos templos» de Gonzalo de Castro (1858-1905), se presenta una catedral y una fábrica como glorificadoras, ambas, de Dios, al que respectivamente encienden «el humeante hachón de los altares / y la eléctrica luz de los talleres»: una síntesis que no siempre se resuelve tan armónicamente en la literatura del período. 
da. Y nótese, de paso, cómo esta naturaleza dotada de espíritu concuerda armónicamente con una suerte de panteísmo al que quisieron los krausistas revestir con la máscara del «panenteísmo»; aunque esta cautela doctrinal no les sirvió, no obstante, para librarse de las invectivas doctrinales de los intransigentes «católicos a machamartillo» como Menéndez Pelayo, que vieron en la religiosidad de los adeptos a la «novísima filosofía» de Krause y su apóstol español Sanz del Río una variante apenas simulada del denostado panteísmo.

Otros caracteres románticos no penetraron con el primer Romanticismo europeo, o lo hicieron con retraso y como al sesgo, sin la intensidad que cobrarían en la cultura española ya a finales del siglo XIX. Influencias como la de Heine, por ejemplo, se dejan notar en la formación de los poetas prebecquerianos y en el propio Bécquer -al menos desde las traducciones de diversos poemas del Intermezzo lírico publicadas en El Museo Universal (1857), que Julio Nombela y Bécquer trataron de imitar-; pero la de su coetáneo Leopardi no fecunda el humus cultural español hasta el fin de siglo, donde encarna literariamente el nihilismo pesimista más sombrío (Prieto de Paula, 1991 y 1997); por más que en 1855 diera ya Valera cuenta de la importancia de sus cantos (Valera, 1942). El caso de Leopardi no es del todo excepcional: muchos de los efluvios más impregnantes y duraderos del Romanticismo europeo afectaron con mayor intensidad a la España simbolista que a la romántica. Añádase a ello el hiato existente en el Romanticismo español entre creación y teoría, algo que no se produce en otras literaturas nacionales como la alemana, la francesa o la italiana (Silver, 1985: 13). Por esta razón una parte de las influencias creativas europeas de comienzos del XIX cayeron en saco roto al no poderse incorporar su fundamentación intelectual, y sólo fueron aprovechadas por los poetas españoles cuando, en la plenitud simbolista, estaban naturalizadas y ya no representaban una novedad emergente; pues es bien cierto que muchos de los signos del alto romanticismo europeo entraron en España «directa o indirectamente, por ejemplo a través del simbolismo francés» (Silver, 1996: 110). Ante esta recepción, los poetas del fin de siglo hubieron de despejar la parte más enfática, pomposa y granditonante del Romanticismo, esa que mostraba tantas contigüidades con la poesía astral de los poetas osiánicos, tal como puede apreciarse en ciertas composiciones de Espronceda, y en general en la musicalidad ostentosa de su obra. Cierto que en esta tarea les había precedido Bécquer, quien se asienta en esta primera gran falla de la Modernidad -que los primeros románticos españoles no habían aún captado-, acomodado «en la brevedad cortante de las impresiones» o «en el estilo vivo de las ruinas» (García Montero, 2001: 32). 
En una reseña que hace a Colección, libro de poemas de José Moreno Villa de 1924, mostró Antonio Machado una asombrosa lucidez teórica, si bien retrospectiva, al caracterizar la poética simbolista como rezumo del irracionalismo filosófico. Los simbolistas («poetas de antes de ayer», escribe) son los habitantes de un tiempo -segunda mitad del XIX- en que se muestran al aire «las raíces del ente de razón cartesiano», de donde la inteligencia resulta privada de su papel principal, convertida en mero instrumento de una acción no regida, sino sólo propulsada, por su propia y schopenhaueriana voluntad. Asentada en un territorio del irracionalismo, la poesía simbolista, en su pretensión de sacar al exterior el subconsciente, se opone a lo meridiano, apaga la luz del optimismo leibniziano y abre las compuertas de la oquedad metafísica (Machado, 1988: 1655). Ahí están algunas claves de la estética a la que el propio Machado contribuyó, aunque luego cercenara las derivaciones necesarias de la misma: la subversión surrealista entre todas. Es éste seguramente el motivo de que, pese a su simbolismo originario, Antonio Machado sea, con el tardío poeta Unamuno, el gran poeta del siglo XIX, como llegó a afirmar con razones creo que fundadas Luis Felipe Vivanco. Pues si la estética simbolista comportaba un avance hacia los territorios embriagadores del espíritu, tan atractivos como desdibujados pero, en todo caso, ya no pilotados por la razón, Machado se colocó en los oídos, como Odiseo, tapones de cera para no naufragar fatalmente en las playas irracionalistas adonde apuntaba la proa del Simbolismo. A esta alteración del avance previsto en los códigos de su poética se debe la turbación crítica que produce la trayectoria de Antonio Machado, donde no hay una evolución en sentido progresivo y lineal, sino una a modo de retractación de ciertos rasgos bien presentes en su libro de 1903, Soledades; lo que provocó, en mi opinión, determinadas exageraciones y yerros interpretativos, como cuando Cernuda habla de que Antonio Machado «nace formado enteramente, y el paso del tiempo nada le añadirá, antes le quitará» (Cernuda, 1957: 88). Su libro siguiente, Campos de Castilla, aparece bajo el frontispicio del «Retrato» inicial ( «Mi infancia son recuerdos...»), lo que, sin presentarse como una palinodia, en bastante medida lo era ${ }^{3}$. El Machado simbolista de los comienzos se hinche de

${ }^{3}$ Así es como cabe entender los tres serventesios en que Antonio Machado trata de su poética: «Adoro la hermosura, y en la moderna estética...», «Desdeño las romanzas de los tenores huecos...», «¿Soy clásico o romántico? No sé, dejar quisiera...». El poeta declara su afección a la «moderna estética» (Modernismo, Simbolismo), aunque desprovista de los «afeites» artificiosos ( $1^{a}$ estrofa), identificables con la poesía de los «tenores huecos» ( $2^{\mathrm{a}}$ estrofa) que sustituye la voz sustantiva por los ecos y las adherencias ornamentales; y concluye ( $3^{\mathrm{a}}$ estrofa) con una declaración de principios de carácter ya extrapoético, cuando expresa su deseo de ser recordado -aun cuando aceptemos que se trata de ser recordado en tanto que poeta- por su entidad ética más que por su dominio artístico. No sé si esta declaración de principios, tan decantada hacia un extremo en la tercera estrofa, hubiera sido escrita de este modo de no haber sido Machado autor de Soledades. El poema unamuniano correspondiente a este poema es «A la corte de los poetas», de Poesías, cuyo título remeda el de la antología de comien- 
concepto en Campos de Castilla, e incluso enlaza, en los poemas proverbiales de este libro y del siguiente -Nuevas canciones-, con el discurso gnómico de parénesis e ingeniosidades $-\langle\mathrm{El}$ ojo que ves no es...»-, que se ha puesto en relación con el haikú, aunque la tiene mucho más estrecha con la creación sentenciosa de Campoamor.

Si entendemos el Simbolismo como un hito a mitad del camino que va desde el Romanticismo a las Vanguardias, comprenderemos la presencia del irracionalismo rampante al que se refería Antonio Machado en la reflexión aludida. El racionalismo humanista había ido empujando a los dioses contra un muro, pero él mismo cayó en descrédito tras la obturación metafísica representada por la filosofía kantiana, cuyo componente ilustrado no oculta la desesperanza. Arrumbada la metafísica como un montón de escombros, en la segunda mitad del siglo XIX adquieren masa y consistencia las grandes corrientes irracionalistas en filosofía, que habrían de dejar su estigma en la lírica. Por eso la poesía del Simbolismo presenta al hombre tras una victoria pírrica: debelador de los dioses a los que ha dado muerte, erigido en solitario sobre un campo de ruinas. Ese campo de ruinas es el territorio desolado de la razón, inicialmente sustituta de la religión en retirada, y al cabo incapaz de llenar el hueco que ella misma había abierto en la confianza de los humanos. La razón es, en fin, el payaso de las bofetadas hacia el que poetas, ensayistas y novelistas de la estela del 98 dirigen sus denuestos.

La desconfianza en la razón, a la que paradójicamente habían llevado los sacerdotes de la misma, no supuso en su origen una ruptura con el logos cartesiano, pues se llegó hasta ella como a una meta con la que no se contaba, después de que las corrientes ilustradas hubiesen declarado la incognoscibilidad de la cosa en sí kantiana. Ahí se contenía el germen de la irracionalidad y la liquidación del optimismo metafísico por parte de los filósofos del pesimismo. Si en el Romanticismo este pesimismo había sido contrarrestado por la añoranza de un mítico tiempo de plenitud, en los umbrales de 1900 ya no se aliviaba con retrospecciones idílicas, ni con la ignorancia de los dudosos logros que había conseguido el pensamiento moderno. La ignorancia rural o aldeana fue el alimento de una literatura ingenuista o en algunos casos costumbrista que, todavía en diversos autores de fines del XIX o comienzos del XX, aparentaba estar nostálgicamente establecida en un mundo que se disolvía ante la revolución tecnológica, la suplantación de la aldea por la polis y el nacimiento de una vitriólica modernidad que no se conformaba con escrutar desde fuera el rostro de la Esfinge, sino que soli-

zos de siglo (Madrid, Pueyo, s.a. [1905]) que se inscribe en la polémica sobre el Modernismo, y en donde el «coro de los grillos» machadiano se convierte en orfeón de «castizas ranas» que, junto a la «charca muerta de la corte», «concierto de sonoras voces / alzan al cielo». 
citaba introducirse cognoscitivamente en ella. La ciudad suponía la concreción y la instigación de una nueva sensibilidad, ya propiamente simbolista (Benjamin, 1971). Frente a ella y lo que ella representaba, muchos espíritus de sensibilidad simbolista no evolucionada se nutrieron del lirismo blanco, melancólico y sencillo en la línea de Francis Jammes (De l'Angélus de l'aube à l'Angélus du soir, 1898), o de las estampas de conservadurismo ruralista de un, por ejemplo, Gabriel y Galán. «El ama», del extremeño-salmantino, al igual que cualquiera de sus cuadros costumbristas de placidez campestre, no es, desde luego, equiparable a «Il sabato del villaggio» leopardiano, ayuno como está de esa melancolía mítica tan aguda en el de Recanati, sin entrar en las distancias insalvables de calidad entre ellos; pero apunta a una plenitud idílica, a la que no puede acceder la poesía alicorta de Gabriel y Galán, que mucho antes de llegar ahí embarranca en el telurismo costumbrista, muy lejos de las sendas ya casi inaccesibles en las que se pierde Leopardi.

Pero existen determinados rasgos -no retraídos en exclusiva al simbolismo, pero también referidos a él- que hay que sumar al de la preeminencia irracionalista, y que, aunque conectan tangencialmente con algunos otros ya comentados, precisan un tratamiento diferenciado dada su densidad ontológica. Más atrás se ha comentado la atenuación del descriptivismo referencial como una nota común del simbolismo latente en parte de la poesía posterior al Renacimiento. Pues bien, la intensificación de esa inclinación en la lírica moderna está relacionada con un proceso de subjetivación sistemática, consistente en la sustitución de la primacía del mundo exterior por el espacio interior en que ese mundo incide. Este factor estaba ya inscrito en el desbordamiento romántico del yo que, desde finales del siglo XIX, iba a arrumbar los débiles muros que mantenían la separación de los géneros literarios. La omnipresencia de un yo en última instancia reflexivo, que pretendía ser al tiempo el sujeto y el tema -un yo que habla de sí-, no puede interpretarse fuera de un ancho espíritu de simbolización poética. En su virtud, el creador ya no se conforma tan sólo viendo el «mundo traidor» con el «cristal con que se mira», como señalara con un punto de cinismo Campoamor, sino que termina sustituyendo lo uno por lo otro, de manera que la particular entonación psíquica del poeta empequeñece y aun suplanta al objeto.

En su Compendio de Estética, Krause había establecido el elemento del yo -la mayor o menor presencia de la subjetividad- como tajo discriminador entre los géneros literarios que la tradición había ido conformando. En la épica desaparece la persona del autor, y esta objetividad es común con la poesía dramática en lo que atañe al creador (no a los personajes, que, como en la lírica, revelan su vida interior); en tanto que en la poesía lírica «la belleza percibida, sentida e 
informada puede serlo como momento de la vida interior de una persona, representada por esta persona misma, como objeto íntimo y peculiar suyo, subjetivo» (Krause, 1995: 120). Pero no tratamos aquí el desplazamiento de los géneros literarios no líricos, novela o drama, por el lírico; sino su colonización por una subjetividad de raíz poética. La mayor espesura del ego succionaría todos los compartimentos genéricos hacia la lírica -0 , mejor, hacia lo lírico-, lo que debía ir inexorablemente acompañado de una merma en la consistencia del $i d$, de la cosa o de la representación de la cosa. De esta manera, la dilución que viven los géneros literarios a principios de siglo debe explicarse por esa invasión de un yo omnipresente, aunque no necesite de la ostentación teatral del romanticismo. Esta invasión, se ha apuntado, supone un acomunamiento de los géneros sobre el bastidor esencial de la lírica, que no en balde ni por azar es el género del yo por definición, en la misma dirección y sentido en que el siglo XX, según vio Pedro Salinas, aparece indeleblemente marcado por el signo lírico (Salinas, 1983: 181$189)^{4}$.

Visto así, nadie debería extrañarse de la suplantación del objeto por parte del sujeto, fenómeno que se percibe lógico; pero el tránsito desde la exterioridad objetiva hacia la intimidad subjetiva no se detiene cuando llega al sujeto, sino que continúa avanzando hacia la mandorla central de la palabra poética, como un abismamiento centrípeto desde el círculo exterior de un sistema concéntrico hasta el círculo más pequeño. En ese círculo interior se sitúa la palabra, que ha vivido siempre su particular desasosiego derivado de su vocación ontológica -y frustrada- de ser objeto, y no sólo de figurarlo, representarlo o decirlo. El topos sanjuanista y simbolista de la cortedad del decir es sólo una parte de ese lamento ontológico, que se personaría en Schiller, así como en lo mejor del Romanticismo inglés y, por difusión, en aquellos autores del siglo XX que han ido más lejos en el camino hacia la autonomía demiúrgica del proceso creador (Rilke, Juan Ramón Jiménez). Que la utilización intransitiva de la palabra proviene de una tradición simbolista parece a estas alturas evidente, en la línea de la «consideración del texto como universo autónomo e irreductible» (Scarano y Ferreyra, 1996: 33). Dese un paso más y tendremos ya una palabra autogenerativa, negadora del carácter representativo del lenguaje, término al que apuntaría el último Heidegger y en el que se radicaría Derrida. Esa palabra es autogenerativa porque contiene sus desarrollos futuros, según un vuelo de «palabras en libertad», patéticamente libe-

+ Aunque, para no pecar de tramposo, diré que la caracterización de ese signo lírico del que habla Salinas no está, al menos explícitamente, basada en la hipertrofia de la subjetividad, sino en el «tono poético» relacionado con la inestabilidad de los sentimientos de la época y la conmoción de la sensibilidad. 
radas de su detestada condición ancilar respecto del sujeto; sólo que, al escoger «ser como Dios» siguiendo la estela de Luzbel, han caído en el infierno vanguardista de la ausencia de significados. No otra cosa es el «orgullo satánico» del que habla Núñez de Arce en su poema «En el monasterio de piedra (Aragón)» (Gritos de combate, 1875), aunque refiriéndose expresamente al ateo, que dejaría de serlo ante la contemplación impresionante de la naturaleza; pues el satanismo del deseo de creación lo sujeta a la misma condena de Prometeo, acosado sempiternamente por «el cieseo, / iay!, que, como el dolor, es infinito». El afán de creación va de la mano del de inmortalidad, en cuanto que uno y otro nos homologan a los dioses. Juan Ramón Jiménez conecta ambos anhelos, el de la creación -literaria, en su caso específico- y el de la inmortalidad personal, en un poema de Belleza (1923) en que aparece tan sólo una cara de este mito jánico, como es la creación sin el subsiguiente dolor prometeico (Jiménez, 1990: 151):

¡Crearme, recrearme, vaciarme, hasta que el que se vaya muerto, de mí, un día, a la tierra, no sea yo; burlar honradamente, plenamente, con voluntad abierta, el crimen, y dejarle este pelele negro de mi cuerpo, por mí!

¡Y yo, esconderme

sonriendo, inmortal, en las orillas puras

del río eterno, árbol

-en un poniente inmarcesible-

de la divina y májica imaginación!

Juan Ramón centra el motivo de la composición en la permanencia esencial de su ser, redimido de la destrucción a través de la obra de arte, en la que se adquiere una presencia intemporal a medida que se va vaciando personalmente. Antes que él, y lo mismo que Núñez de Arce, diversos autores se ocupan del tema del poeta prometeico, que se asimila a la rebelión de Luzbel («Non serviam») por pretender ser creador, y que sufre el castigo por ello: la consciencia de sí hozando en sus entrañas, haciéndose notar mediante el dolor que permite el autorreconocimiento, tal como lo tratan Manuel Reina, Enrique Sierra Valenzuela y, desde luego, Miguel de Unamuno. Éste incluyó en Poesías el espléndido y terrible poema «El buitre de Prometeo», monodiálogo con el buitre, al que le insta para que siga royéndole las entrañas, puesto que el hombre se reconoce en el dolor; y

${ }^{5} Y$ nótese la analogía entre la insaciabilidad del deseo y la infinitud del dolor, en relación con la idea schopenhaueriana de que la voluntad -el deseo o el afán de vivir, en suma- genera el dolor constitutivo del ser humano, de donde su invitación a cercenar todo deseo, en sintonía con el budismo nirvánico. 
en Rosario de sonetos líricos consta el soneto «A mi buitre», cuyo simbolismo y sustancia imaginaria son los mismos, por cierto, que varios años después darían cuerpo al «rayo» hernandiano: «Este buitre voraz de ceño torvo / que me devora las entrañas fiero / y es mi único y constante compañero / labra mis penas con su pico torvo» (Unamuno, 1987: 311). A modo de apostilla, «el hambre atroz que nunca se le apaga», último verso del poema unamuniano, no deja de remitir a la voluntad schopenhaueriana, condenada a multiplicarse a medida que se procura satisfacerla: otro emblema del dolor de vivir provocado por las mismas ansias de hacerlo.

En relación con ese anhelo de la palabra por liberarse de la dependencia del objeto, está la presencia de la música, no única ni preferentemente como tema, sino como sometimiento de todo el discurso a las leyes de la medida y del compás, del timbre y del tono, de la consonancia. A veces se reduce la importancia de la métrica en la literatura que llamamos modernista a la utilización de tales o cuales recursos de cómputo silábico o de disposición acentual, en los que, ya lo sabemos, Juan Ramón, Tomás Morales, Fernando Fortún o Villaespesa son maestros. Si sólo fuera eso, habríamos de convenir que dicha «revolución» la habían anticipado al menos en parte otros autores no estrictamente simbolistas. Pero la importancia que la música tiene aquí es, además, de otra índole. La música supone también, y quizás antes que cualquier otra cosa, la habilitación de un discurso paralelo y correlativo al referencial; lo que implica, en línea con lo que se ha dicho atrás, arrojar por la borda el lastre de la excesiva servidumbre respecto de la semántica. Unamuno, que no era músico pero sí sabio, relacionó esta actitud con una entrega narcotizante que se contraponía, en su particular manera de entenderlo, a la poesía musculada de ideas y densa de sentimientos. «Algo que no es música es la poesía» es la contestación tajante de Unamuno a la conocida propuesta verlainiana: su inclusión en el «Credo poético», inmediatamente después del poema introductorio « ¡Id con Dios!» con que se abre Poesías, da cuenta de su carácter programático y su centralidad estética.

Concluyamos. Poesía situada en el más allá, subjetivación sistemática, irracionalismo, preeminencia de la música: he aquí las bases sobre las que se levanta la poesía española en torno a 1900 (y me costaría poco decir que la europea, si ajustamos las fechas a las características culturales de cada país). De la mano del pesimismo metafísico postkantiano, y de ese vitalismo dionisíaco que encontró en Nietzsche a su más preclaro profeta, el irracionalismo ambiental contaminó la literatura, que abandona el campo del logos y se adentra en las bodegas de lo subconsciente que comenzó a explorar el Rimbaud de las Iluminaciones, en un proceso que no pararía hasta los engendros de la escritura automática bretonianos. 
Una vez se abrieron las esclusas de la irracionalidad, el poema terminó anegándose de los detritos de la razón, reducida a un vértigo de contingencias, en un movimiento compulsivo e irrefrenable, sin moderación ni medida. «QQué son, decidme, al cabo las verdades / sino aquellas mentiras que creemos?», había escrito Manuel Machado -al alimón con Enrique Paradas- en Tristes y alegres (1894). Al final, el dominio al que se refiriera Antonio Machado de «la música de Wagner, el poema sonoro de la total opacidad del ser, cuya letra era la metafísica de Schopenhauer» (Machado, 1988: 1655) constituyó una primacía que condujo a la razón hacia una huelga de brazos caídos, cuya expresión más patética fue la subversión surrealista.

\section{BIBLIOGRAFÍA CITADA}

Aullón De HARO, Pedro. 2000. La modernidad poética, la vanguardia y el creacionismo, ed. de Javier Pérez Bazo, Anejo XXVIII de Analecta Malacitana, Málaga, Universidad.

BENJAMIN, Walter. 1971. «Sobre algunos temas en Baudelaire», en Angelus novus, Barcelona, Edhasa.

CAMPOAmor, Ramón de. 1890. Poética, Valencia, Librería de Pascual Aguilar.

CERNUDA, Luis. 1957. Estudios sobre poesía española contemporánea, Madrid, Guadarrama.

García Montero, Luis. 2001. Gigante y extraño. Las «Rimas» de Gustavo Adolfo Bécquer, Barcelona, Tusquets.

HJelmslev, Louis. 1974. Prolegómenos a una teoría del lenguaje, Madrid, Gredos.

JiméNEZ, Juan Ramón. 1990. Selección de poemas, ed. de Gilbert Azam, Madrid, Castalia.

Krause, Karl C. F. 1995. Compendio de Estética, trad. de Francisco Giner, ed. de P. Aullón de Haro, Madrid, Vérbum.

Machado, Antonio. 1988. Poesía y prosa, III, edición crítica de Oreste Macrí, Madrid, Espasa Calpe / Fundación Antonio Machado. 
Prieto de PAUla, Ángel L. 1991. «Desde Leopardi a los escritores españoles de fin de siglo: hacia una caracterización del 'mal de la tierra'», Quaderni di Filologia e Lingue Romanze, $3^{\text {a }}$ serie, núm. 6, pp. 63-80.

Prieto DE PAula, Ángel L. 1997. «Claves de la desesperanza: leopardismo y schopenhauerismo en la literatura española del Novecientos», Quaderni di Filologia e Lingue Romanze, $3^{\mathrm{a}}$ serie, núm. 12, supplemento, pp. 6:-75.

Salinas, Pedro. 1983. «El signo de la literatura española del siglo XX», en Ensayos completos, III, Madrid, Taurus.

SCARANo, L. y Ferreyra, M. 1996. «La poética especular del Modernismo: e1 gesto fundador de Darío y Jiménez», en L. Scarano et al., Marcar la piel del agua. La autorreferencia en la poesía española contemporánea, Rosario (Argentina), Beatriz Viterbo Editora.

Silver, Philip W. 1985. La casa de Anteo. Estudios de poética hispánica, Madrid, Taurus.

SILVER, Philip W. 1996. Ruina y restitución: reinterpretación del Romanticismo en España, Madrid, Cátedra.

Unamuno, Miguel de. 1987. Poesía completa, I, Madrid, Alianza.

VALERA, Juan. 1942. «Sobre los Cantos de Leopardi», en Obras completas, Madrid, Aguilar. 